\title{
DIE ONTWIKKELING VAN DIE BEDRYFSEKONOMIE
}

Rede uitgespreek by die aanvaarding van die Professoraat in die Bedryfsekonomie aan die Universiteit van Pretoria op 24 Maart 1949

\section{deur Dr Ir J. Goudriaan}

Lede van die Raad,

Meneer die Rektor,

Dames en Here Professore, Lektore en Dosente,

Dames en Here Studente,

En voorts u almal, wat hierdie plegtigheid met $u$ teenwoordigheid vereer,

Geagte toehoorders,

Die pragtige seereis van Nederland na Suid-Afrika, wat 'n mens dae lank niks laat sien as see en lug en hulle altyd veranderende aansigte, het my aan die dink gebring oor die ontwikkeling van my eie vak, oor die resultate bereik in die laatste tientalle jare en oor die moontlikhede vir die toekoms.

Enkele resultate van hierdie oordenkings wil ek hier gee.

Die bedryfsekonomie het tot taak om ons wetenskaplike insig te verskaf in die middéls en metodes om 'n bedryf so doelmatig moontlik te lei.

Met hierdie korte sin is 'n besonder ingewikkelde samestel gegee van vraagstukke van baie uiteenlopende aard.

'n Mens hoef net sy oë te laat gaan oor die hele ekonomiese lewe om hom die verskeidenheid te laat besef van wat ons met die enkele woord bedryf omvat. Ons sien bedrywe in die landbou en die veeteelt, in die bosbou en vissery, in die mynwese, fabrieksnywerheid, transport, bankwese, in die groot- en in die kleinhandel. Ons sien bedrywe met duisende of tienduisende werknemers, soos Eskom en Yskor en bedrywe met net 1 of 2 man personeel. Ons sien bedrywe in die besit van een alleeneienaar of in die besit van vennootskappe, maatskappye, koöperasies of van die Staat of die stad of van kombinasies van hierdie kategorieë van eienaars.

Dit is geen wonder dat in die begin mense daaraan gewanhoop het om ooit die verskillende vraagstukke in die verskillende soorte ondernemings onder gemeenskaplike gesigspunte te bring en so het ons die ontwikkeling gesien van $n$ aantal verskillende bedryfsekonomieë, elk vir $n$ bepaalde soort van besighede. Ons vind dit ook nou nog in die landbouekonomie en in sommige lande in die verkeersekonomie. Maar ek durf die verwagting uitspreek dat in die toekoms die kontak tussen die verskillende lede van die groot familie versterk sal word, omdat ons wederkerig van mekaar kan leer en die besondere vraagstukke van een bepaalde bedryfstak soos die landbou of die transportwese byna altyd ook sekere betekenis het vir bedrywe buite hierdie bedryfstakke en omgekeer.

Die besondere uiteenlopendheid van die vraagstukke binne een en dieselfde bedryf het in die eerste jare van die ontwikkeling van die bedryfsekonomie nog tot andere splitsings gelei. Rekenmeesters, ingenieurs, fisioloë, psigoloë en opvoedkundiges het hulle, ieder met sy eie gesigspunte, met bedryfsekonomiese vraagstukke besig gehou en baie nuttige werk verrig. Maar ons ontkom nie aan die indruk dat die een- 
sydigheid van hulle uitgangspunte soms sekere gevare meegebring het nie. Byna elke vraagstuk van die bedryfsekonomie is immers van samegestelde aard.

Die lewe van elke bedryf is 'n samewerking van mense en dinge, van arbeid en kapitaal; elke bedryf staan deur inkoop en verkoop, deur kredietneming en kredietverskaffing in verbinding met die buitewêreld; in vry wel alle bedrywe, as ons 'n oomblik afsien van die suiwere handel en die bankwese vind heur fabrikasie, verpakking of transport sekere omsettings van waarde plaas; elke bedryf het vir sy voortbestaan 'n boekhouding nodig soos al beliggaam is in die ouuitdrukking: Wat skryf die blyf.

Elke maatreël op een van hierdie gebiede het dus meestal 'n sekere invloed op die ander gebiede. Die beste oplossing word dan alleen verkry as ons die verskillende gesigspunte na mekaar die woord gee en dan soek na die maatreël wat al die verskillende gesigspunte op die beste manier bevredig.

In die meeste bedrywe en veral in die grote het dan ook ' $n$ spesialisasie gegroei vir die verskillende take. Min of meer bewus het ons oral die rigting gevolg wat Taylor byna vyftig jaar gelede aangewys het: .. Onder die opperste leiding sal elke man so min moontlik verskillende funksies uitoefen." 1)

Die eerste en vernaamste splitsing het ons hierbo al geskets. Dit is die taakverdeling tussen die ingenieur, die koopman, die finansier, die rekenmeester en die maatskaplike werker in die bedryf. En die gedagte lê voor die hand om die bedrysekonomie ook soveel moontlik in hierdie vyf hoofstukke in te deel en daaraan toe te voeg 'n sesde hoofstuk vir die algemene leiding.

Die funksieverdeling in die bedrywe moet ons mos sien as 'n voorbeeld van die algemene groeiwet van alle lewende organismes soos Herbert Spencer, die beroemde Engelse sosioloog al vir 'n halwe eeu gelede uiteengesit het: ' $n$ voortdurende toeneming van die differensiasie, van die min of meer bewuste skepping van gespesialiseerde organe vir verskillende funksies met as teenpool 'n sterk drang tot integrasie om hierdie verskillende funksies in goeie onderlinge harmonie te laat werk.

Die bedryfsekonomie is mos niks anders as 'n onderdeel van die toegepaste sosiologie wat op sy beurt ' $n$ deel is van die biologiese wetenskappe. Hierdie analogie met die evolusie van lewende organismes uit die plante- en dierewêreld kan ons ook laat besef dat daar gladnie gepraat kan word van oorheersing van een van die vyf fijnksies oor een of meer van die andere nie. Hulle is al vyf ondergeskik aan die algemene leiding van die bedryf; die veronderstelling daarenteen dat een van hierdie vyf funksies die baas kan wees oor een van die ander is ewe ongerymd as die gedagte dat die asemhaling vir die menslike gesondheid belangriker is as die bloedsomloop of die spysvertering.

Die beperktheid van die menslike arbeidsvermoë en van die menslike intellek maak dat dit vir die oorgrote meerderheid van die besigheidsmense wenslik is dat hulle in een of twee hoofstukke van die bedryfsekonomie spesialiseer maar dit wil niet sê dat hulle van die ander hoofstukke heeltemal onkundig mag bly nie. Inteendeel: onbekend maak onbemind. Die enge, kameraadskaplike samewerking in die bedrywe sal nooit bereik word as elke verteenwoordiger van 'n bepaalde funksie nie ook globaal kennis dra van die vraagstukke en van die moontlikhede

1) Frederick Winslow Taylor: Shop Management 1903, bls. 99. 
en moeilikhede van die ander funksies nie. Daarom is 'n ruime, algemene inleiding in die bedryfsekonomie vir alle studente in die vak onontbeerlik as grondslag vir latere spesialisasie.

Daarom juig ek dit ook toe dat die voorlesings deur die nuwe Institut vir Bestuur en Administrasie in die voetspoor van die Graduate School of Business Administration van die Harvard Universiteit vir 'n groot deel sal geskied volgens die sgn. "Gevalle metode." Hierdie metode is beter as enige ander daartoe geskik om die studente die samegestelheid van alle bedryfsvraagstukke te laat besef en die nadruk te lê op die noodsaaklikheid om na harmonie te streef tussen die verskillende, dikwels teenstrydige gesigspunte van die verskillende funksies.

Die metode is ook by uitstek geskik om die studente te leer om beslissings te neem; dit prikkel die aktiwiteit, die belangrikste vereiste vir die besigheidsman.

Maar ek kan my kollegas van die Harvard Universiteit nie volg as hulle die gevalle-metode as die enigste aanprys nie en alle teorie wil afskaf. Juis die analitiese dinkmetode moet ons die algemeen geldige insig verskaf in die voorwaardes wat noodsaaklik en voldoende is om 'n bepaalde oplossing bo ander te verkies. Dis nie alleen sierliker nie maar op die duur ook baie vinniger en betroubaarder as om vir elke geval afsonderlik, telkens opnuut die beste oplossing te soek.

Hierdie teoretiese analise maak dit ook moontlik om alle bedrywe hoe uiteenlopend ook in aard of omvang, met een samevattende blik te oorsien en so die vrugbare uitwisseling en oordrag van ervarings ook tussen die mees verskillende bedryfstakke te bevorder. Die indeling van die bedryfsekonomie volgens hooffunksies is van die analitiese metode ' $n$ eerste maar belangrike voorbeeld, omdat dit laat blyk dat, ook as bedrywe in een bepaalde funksie, soos die tegniese, baie uiteenloop, hulle tog in andere funksies voor dieselfde vraagstukke kan staan.

Laat ons sien wat die ontwikkeling van die laaste tientalle jare vir die verskillende funksies opgelewer het.

Laat ons daartoe begin met die boekhouding. Dit is die oudste funksie in die bedrywe wat 'n sekere wetenskaplike behandeling gehad het en dit neem ' $n$ aparte plaas in omdat die boekhouers, in teenstelling met alle ander uitvoerende mense in die bedryf, geen eintlike dade van beheer verrig nie. Hul taak is net soos die naam so duidelik aandui, om boek te hou van wat andere gedoen het. Dit was $n$ saak van goeie menslike insig om al in vroeë tye hierdie taak van boekhou van die uitvoerende werksaamhede te skei.

Die oudste vorm van boekhouding wat ons ken het betrekking op handelsake. Die metode van dubbele inskrywing was reeds in die middel van die veertiende eeu in Genua bekend; die leerboeke het, soos so dikwels in die toegepaste wetenskappe, eers later verskyn. Van die oudste gedrukte verhandeling van die Italiaanse Fransiskaanse Monnik Pacciolo (1494), van die Antwerpenaar Ympyn (1543), van Claes Pietersz van Deventer (1576) en van die veelsydige Renaissance skrywer Simon Stevin (1608) — groot wiskundige, vestingboukundige en herskepper van die Nederlandse taal - loop 'n deurgaande lyn na die beroemde boek van Léautey en Guilbault, wat in 1889 verskyn het, die goue medalje verwerf het op die Wêreldtentoonstelling in Parys van daardie jaar en sedertdien omstreeks vyftig herdrukke beleef het. 2)

Vir ons is die boek van die twee Franse skrywers die bekroning èn

2) La Science des Comptes, mise a la portée de tous. Parys, Béranger.

m a b blz. 228 
die afsluiting van vier eeue boekhoutegniek. Hierdie boek gee 'n glasheldere uiteensetting van die sierlike en logiese metodiek van die dubbele inskrywing; maar tegelyk vir die eerste keer 'n formulering van een van die hoofbeginsels, waarop die klassieke boekhouding berus, 'n beginsel wat die mense al die eeue wel gevolg het, maar niet so bewus gesien het nie: die beginsel van die behoud van die waardes binne die bedryf.

in Beginsel wat tot vandag, veral in die Angelsaksiese lande die grootste belemmering gewees het vir die aanpassing van die boekhoumetodes aan die eise van die moderne bedryfsleiding.

Hoe het die konflik ontstaan en wat is die oplossing?

Die klassieke boekhouding is in oorsprong die boekhouding van die handelsake; miskien mag ons sê die boekhouding van groothandelsake wat per party ingekoopte goedere hulle rekenings opmaak. Die Italiaanse handelsrepublieke waar die klassieke boekhouding ontstaan het, later Antwerpen, Amsterdam, Londen, Parys, Hamburg en Nu York is van die soort stapelhandel die setel gewees. ${ }^{3}$ ) Vir hierdie sake was die beginsel van die behoud van die waardes binne die bedryf wat sê: verlies of wins kan alleen ontstaan by verkoop aan derdes buite die bedryf, volstrek geen belemmering, maar iets vanselfsprekends. Hul het dit natuurlik aangevul met die nog altyd juiste beginsel van balanswaardering: goedere neem ons hoogstens op teen markprys of koopprys, watter van die twee die laagste is; dit was reeds aan die skrywers uit die sestiende eeu bekend en sal, sover ons kan sien, nog eeue lank goed bly.

Maar die moderne sake, soos huile gegroei het in die negentiende en twintigste eeu verskil radikaal van die ou groothandel: hul het baie groter en ingewikkelder geword, die kombinasie van nywerheid en handel beteken allerhande waardeomsettings binne die bedrywe, hul gebruik veel groter kapitaal, dikwels met verantwoordelikheid teenoor derdes wat as aandeelhouers of kredietgewers optree en veral: deur hul grootte en verantwoordelikheid teenoor kapitaal en arbeid streef hulle meer bewustelik na duursaamdheid en stabiliteit.

Die alles oorheersende gedagte van die moderne bedryfsleiding is: vooruitsien in die toekoms sover as dit maar moontlik is, so vroeg moontlik nuutopkomende moontlikhede en moeilikhede ontdek om so vinnig moontlik maatreëls te neem om ons daarby aan te pas. As Taylor die naam verdien van die grondlegger te wees van die wetenskaplike bedryfsleiding, dan is dit veral omdat hy die eerste en die kragtigste vir die algemene gedagte van die ,planning", die planmatige vooruitsien gepleit het. ${ }^{4}$ )

Die tyd van die Koopliede-avonturiers, van die Merchant adventurers, is verby; die gedagte van die wetenskaplike analise het op al die verskillende velde van die bedryfsleiding toepassing gevind; dit beteken dat die begroting of beraming van allerhande toekomstige bedryfsverskynsels, wat ons met een woord sal aangee as die voorkalkulasie, 'n baie belangrike plaas in die moderne bedryfsleiding inneem. Die ou gesegde: besin eer jy begin, het 'n konkrete toepassing gevind.

Maar die maak van planne vir die toekoms het geen praktiese betekenis

3) Die leser kry, miskien beter as uit dikke leerboeke 'n lewende indruk van hierdie handel en sy boekhouding uit die roman Ferdinand Huyck van Jacob van Lennep; sien die begin van die agtiende hoofstuk waarin Ferdinand op 'n handelskantoor geinstalleer word.

4) Die woord Scientific Management is die eerste gebruik in 1910 deur n' groep van ingenieurs; in 1911 het Taylor se boek oor "Principles of Scientific Management" verskyn wat die woord algemene bekendheid gegee het.

$\mathrm{ma} \mathrm{b}$ blz. 229 
nie as ons die uitvoering nie op die voet volg nie en daarom streef ons altyd na die noukeurige vergelyking tussen voor- en nakalkulasie, tussen die berekenings wat ons gemaak het voordat die betrokke verskynsels hulle voordoen en die berekenings oor die verskynsels soos hulle werklik plaasgevind het.

Hier lê nou presies die veld waarop die nuwe eise met die beginsels van die klassieke boekhouding gebots het.

As ons die vergelyking tussen voor- en nakalkulasie so eenvoudig en noukeurig moontlik wil makk en omring met al die waarborge wat die dubbele inskrywing daaroor verskaf moet ons die voorkalkulatoriese waardes in die boekhouding invoer en die verskille tussen voor-en nakalkulasie as verliese of winste aanvaar. Daarmee het ons dan die beginsel van die behoud van die waardes binne die onderneming prysgegee.

Omgekeerd: as ons hierdie beginsel wil handhaaf is ons verplig om die vergelyking tussen voorkalkulasie en nakalkulasie extrakomptabel, d.w.s. buite die boekhouding te maak en ons verval daarmee in baie ekstra werk en 'n hoop onsamehangende state wat nooit die regte oorsigtelike verband met die boekhouding kan gee nie.

Die Amerikane, wat eerste die algemene eis van voorgekalkuleerde kospryse en hulle voortdurende vergelyking met die nakalkulasie vanaf 1910 of 1920 op die voorgrond gestel het, het in oorgrote meerderheid die laaste weg gekies en ek glo dat die onoorsigtelikheid van die Amerikaanse literatuur oor hierdie onderwerp hoofsaaklik aan hierdie keuse toegeskryf moet word. Eers na die tweede wêreldoorlog is daar enkele skoorvoetende en halfhartige pogings om die intrakomptabele verband tot stand te bring. 5) Maar die teenstand van die rekenmeesters wat die beginsel van die behoud van die waardes, dikwels on of halfbewus as 'n dogma hanteer, sal in die Angelsaksiese lande die invoering van die intrakomp tabele metode baie moeilik en langsaam maak.

Ons het in Nederland in 1931 vir die internasionale Philips Concern doelbewus die intrakomptabele invoering van voorkalkulatoriese waardes toegepas en ek durf sê dat die resultate baie bevredigend was. Dat dit moontlik was om hierby die medewerking van die Nederlandse rekenmeesters en ouditeurs te verkry moet ons toeskryf aan die voorbreidende werk van Simon, 6) Volmer en Limperg; veral die laasgenoemde het deur sy beskouings oor die noodsaak om die kosprys te bereken op grondslag van die vervangingswaarde die dogma van die "werklike waarde" soos dit voortvloei uit die klassieke boekhouding baie aangetas.

'n Mens kan origens onmiddellik insien dat die invoering van die voor kalkulatoriese waardes in die boekhouding geen enkele gevaar kan oplewer vir die soliditeit van die boekhouding en sy oudste doel die vermoëns- en winsbepaling nie solank ons maar die ou-beproefde voorskrifte handhaaf vir die waardering van bates en laste in die balansstaat.

5) Sien: Rowland and Harr, Budgeting for Management Control. Harper and Brothers, Nu York en Londen 1945, Hoofstuk XX.

6) Simon het al in 1909 in sy boek: Kostprysberekening en Administratieve Fabrieksorganisatie (Delwel, Wassenaar) daarop gewys dat ons die onkoste nie moet verdeel oor die werklike (nakalkulatoriese) bedryfsdrukte niet, maar oor die normale of standaard bedryfsdrukte. Dit is waar dat die Amerikaan Hamilton Church al in 1900 dieselfde gedagte verdedig het. Maar hy schrik terug om die onder- of oordekking op onkoste, wat onvermydelik uit die rekening met standaard bedryfskoste voortvloei, oor te boek na die Verlies- en Winsrekening. Daarom het hy die sogenaamde "Supplementary rate" uitgevind - 'n ekstra omslagtige metode om foutief te reken. Sien sy boek: The proper distribution of the expense burden. Dunlop 1908. The Engineering, Mag., 1921. 
As die waarderings van bates en laste in openings- en sluitbalans dieselfde bly, moet ook die verlies of wins oor die tussenliggende tydvak dieselfde wees, ongeag die waarderings wat ons onderweg in die rekeningsstelsel ingevoer het; hulle word immers, by die waardering in die sluitbalans weer ongedaan gemaak.

Die invoering van voorkalkulatoriese waardes beteken nie dat ons die totale verlies of wins verander nie, maar dat ons hierdie saldo splits op 'n sodanige manier dat ons daardeur 'n skerp insig kry in die plase waar verlies of wins optree en in die oorsake van die verlies of wins. Die verlies en winsrekening van die hele bedryf is dan net die som van 'n aantal verskillende verlies- en winsrekeninge, elk gedebiteer vir bepaalde nakalkulatoriese koste en gekrediteer vir die ooreenkomstige voorkalkulatoriese waardes.

Hoe kan ons die spliting op die beste manier uitvoer?

In die eerste plaas deur verlies- en winsrekeninge te maak per persoonlike verantwoordelikheid. Ons volg daarby die skema van die organisasie en ons kan die verantwoordelikhede net so laag of hoog lê as ons verkies.

Per persoonlike verantwoordelikheid kry ons dan 'n verlies- en winsrekening wat debet staan vir alle verbruike van die afdeling en kredit vir alle prestasies. Maar om die resultate van die afdeling suiwer te meet is dit noodsaaklik dat alle verbruike en alle prestasies teen vaste sgn. standaard pryse in die rekening opgeneem word.

Vir sover die verbruike betrekking het op prestasies van ander afdelings in die bedryf (halfklaar produkte, hulpdienste soos transport, elektriese energie, stoom ens.) is die pryse vir die debet van die verbruikende afdeling gelyk aan die pryse vir die kredit van die produserende afdeling. Vir lone en salarisse debiteer ons die werklike waardes.

Vir grondstowwe buite die bedryf gekoop voer ons vaste pryse in deur tussenskakeling van 'n rekening vir prysverskille; hierdie rekening staan dus debet vir die faktuurwaarde en kredit vir die ingekoopte hoeveelhede omgereken teen standaardpryse.

Vir afdelings soos die algemene direksie, navorsings-laboratoriums ens. voer ons vaste bedrae in, wat diens doen vir die verrekening van die onkoste na ander afdelings; verskille tussen werklike uitgawes en die vaste bedrae is net die verlies - of winssaldo van hierdie afdeling.

Die verkoopsrekening staan debet vir die standaardwaardes van die verkoopte goedere en die reeds genoemde standaardbedrag aan verkoopskoste en kredit, soos altyd, vir die werklike opbrengste.

Die laaste afdeling in iedere bedryf is die verkoopsafdeling, indien nodig gesplits vir verskillende artikelgroepe. Die rekening van die verkoopsafdeling staan dus debet vir die werklike koste, ewentueel bereken teen standaardpryse en kredit vir die standaardbedrag aan verkoopskoste, soos dit volgens die geldende formules belas word aan die verkoopsrekening.

Ons kry dus 'n rekeningskema soos op sterk vereenvoudigde manier aangegee in Tabèl A.

Dit is duidelik dat by stygende pryse die prysverskillerekening 'n debetsaldo moet toon. Dit is die aanwysing dat ons die verkooprekening te laag belas het omdat die standaardpryse van die verkoopte goedere klaarblyklik nie meer ooreenstem met die kospryse bereken op grondslag van die vervangingswaarde nie. As ons die verskille groot en duursaam genoeg ag om daarmee rekening te hou in die kalkulasie, kan ons gemaklik deur middel van indekssyfers bereken hoeveel die prysstyging uitmaak 
op die standaardwaarde van die verkoopte goedere. Ons belas met hierdie bedrag dan die verkooprekening en krediteer vir dieselfde bedrag die prysverskillerekening. Die hele sisteem van standaardpryse soos dit geld vir magasynvoortade van grondstowwe, halfklaar produkte en eindpradukte bly dus onaangetas. Ons kan 'n jaar lank reken met vaste pryse vir al hierdie voorrade en dit beteken ' $n$ groot vereenvoudiging van die kantoorarbeid en 'n veel beter moontlikheid tot kontrole van die voorrade. Die tegniese afdelings word dus deur die prysveranderings heeltemal nie beïnvloed nie en hierdie veranderings het vir hulle ook nie die minste betekenis nie.

As ons per afdeling net die saldo ken van die verlies- en winsrekening sou dit nie voldoende wees vir die beoordeling van hierdie saldo en vir die juiste insig in die maatreëls wat ons eventueel kan en moet neem om 'n ongunstige saldo te verhelp nie. Daarom is 'n noodsaaklike aanvulling op hierdie stelsel van moderne boekhouding die sgn. parsiële kreditering met die standaardwaardes telkens in gedeeltes sodat ons per onderdeel van die koste kan sien waar die verskille ontstaan het. Ons kan natuurlik die splitsing net sover voortsit as ons verkies, maar elke splitsing kos geld aan kantoorarbeid. Dit is daarom goed om aan te dui dat in elk geval 'n splitsing in drie groepe noodsaaklik is, naamlik in: -

1. die variabele koste wat gelyktydig of so goed as gelyktydig met die produksie en verkoop verander, soos materiaalkoste, kragverbruik en 'n sekere deel van die arbeidslone;

2. die variabele koste wat hulle eers na 'n sekere tydsverloop by wysigings in besetting aanpas;

3. die vaste koste, wat op veranderings in die bedrijfsbesetting in die geheel nie reageer nie.

Sien Tabel B.

Belangrike verskille in groep 1 moet onmiddellik ondersoek word; verskille in groep 2 behoort na ' $n$ sekere tydverloop as die besetting weer stabiel is te verdwyn; verskille in groep 3, dus in vaste koste, raak in die produksie nie die verantwoordelikheid van die afdelingshoof nie en raak in die verkoop die algemene verkoopsbeleid, nie die suinigheid van die kostebeheer nie. Splitsing van die vaste koste in die verlies- en winsrekening van die afdeling het daarom geen sin nie.

Die mate van splitsing van die koste van groep 1 en groep 2 moet geheel bepaal word deur die nut wat ons van hierdie splitsing verwag. As daar geen groot verskille is nie, kan ons die splitsing so goed as geheel agterweë laat; by groot verskille en onreëlmatighede in produksie of verkoop sal ons die splitsing ver deurvoer, maar onmiddellik weer nalaat sodra die moeilikhede opgelos is. By geen ander stelsel het die leiding dit so in die hand om die boekhouding uit te brei of te vereenvoudig, binne die raamwerk van ' $n$ in sigself gelykblywende sisteem, as die wat ons so pas geskets het nie.

Dit werk as 'n soeklig wat 'n mens na wins kan laat skyn as en waar hy dit begeer.

Deur die byna volledige afskaffing van die indiwiduele nakalkulasie per order en die konstantheid van alle pryse van voorrade is dit ook baie goedkoper as die klassieke boekhouding of as alle extrakomptabelle metodes.

Sommige mense het as beswaar teen die metode van variabele be- 
groting deur middel van standaardkoste en parsiële kreditering aangevoer dat die afdelingshoofde nie verantwoordelik gehou kan word vir die sluitendheid van sy verlies- en winsrekening nie, omdat hy, veral in die produksie, sy bedryfsbesetting nie selfstandig kan bepaal nie. ${ }^{7}$ ) Hul stel dan voor om beramings van koste te mak vir verskillende grade van besetting, maar ons kan dit nie beskou as 'n verbetering nie. Inteendeel: sodanige berekenings vereis baie werk, hul kan nooit op eenvoudige manier intrakomptabel verwerk word nie, omdat hul nie korrespondeer met die werklike prestasies en ten slotte: ons kan ook langs hierdie weg nie daarin slaag om volstrekte sluitendheid te eis nie, omdat die koste nie alleen afhanklik is van die besetting nie, maar by verandering van die besetting ook van die besetting in vroeëre tydvakke.

Die doel van die bedryfsbegroting van koste is ook nie, soos by die begroting van owerheidsliggame om 'n bindende outorisasie te gee vir bepaalde uitgawes of koste nie, maar om 'n duidelike rigsnoer te gee vir die tegniese en kommersiële leiding, soos die eerste Amerikaanse skrywers so duidelik op die voorgrond gestel het in die titels van hul boeke: Cost Accounting to aid Production 8); Cost Accounting for Sales. 9) Die beoordeling van die verskille tussen werklikheid en begroting is die belangrikste element en hierdie lewende beoordeling kan nie oorbodig gemak word deur gebrekkige statistiese berekenings nie.

Die regstreekse begroting deur middel van die opbrengste teen standaardkoste het ook die onskatbare voordeel dat die afdelingsleiers voel dat hul uitgawes in wese nie begroot word deur 'n kantoor met amptenare nie, maar deur die mark waar die hele bedryf van leef. Die opbrengs van hulle prestasies teen standaardpryse is immers net daardie deel van die markopbrengste wat aan die betrokke afdeling toegeken kan en mag word.

Die ontwikkeling van die moderne kalkulasiemetodes is nie alleen van groot belang vir die tegniese en kommersiële funksie nie, ook die finansiële funksie kan groot voordeel daaruit trek.

Ons het al gesê dat die vernaamste doel van die moderne bedrywe is sekerheid en stabiliteit vir die toekoms. Kan ons daarna streef om altans die skadelike invloed van hierdie veranderings op die lewe van ons bedryf op te hef of te beperk ook solank ons die konjunktuurveranderings nog nie beheers nie?

Die verliese van 'n bedryf in slegte konjunktuur bestaan uit drie dele;

1. Verliese deur prysdaling van die eie produkte benede die eie kosprys;

2. Verliese op vaste of vertraagde variabele koste deur onderbesetting;

3. Verliese deur waardedaling van vaste en vlottende bates.

Die eerste bron van verliese sal ons so aanstons bespreek; die onder 2 en 3 genoemde verliese kan ons deur doelmatige kosprysberekening. wat regstreeks gerig is op doelmatige winsberekening van die onderneming, vrywel geheel uitsluit. Dit beteken natuurlik nie dat ons deur kalkulasie verliese in winste kan omtoor nie; dit beteken eenvoudig dat ons die kalkulasie so moet inrig dat ons in goeie jare deur die kalkulasie gelei word tot die vorming van die nodige reserwes, wat bestem is om

7) Sien Rowland and Harr t.a.p. Hoofstuk III en as navolging P. Bakker. De

Grondslagen van de bedryfsbudgetering. Hoofstuk IV. Stenfert Kroese, Leiden, 1948. Sien ook die goeie uiteensetting by Bourquin: Traité de comptabilitế industrielle avec application des prix de revient standard. Parys, Dunod. 1947.

8) Charter Harrison. Nu York, The Engineering Mag., 1924.

9) F. A. Hilgert, Nu York, Ronald Press, 1926. 
bepaalde verliese in slegte jare op te vang. Hoe dit geskied deur die verliese op vertraagd-variabele koste is onmiddellik duidelijk. Ons moet die winste d.w.s. die oordekkings wat in tyd van stygende bedryfsbesetting op hierdie soort koste ontstaan volledig reserveer, omdat die winste by eerste benadering gelyk is aan die verliese, d.w.s. die onderdekkings wat hierdie koste sal vertoon in tyd van dalende bedryfsbesetting.

Deur die parsiële kreditering - en uitsluitend deur parsiële kreditering - is hierdie verliese en winste afsonderlik bekend.

Vir die vaste koste geld presies dieselfde, as ons die normale besetting, waarop ons die hoogte van die betreffende onkoste-toeslae bereken mos elke jaat opnutut bepaal as 'n so goed moontlike skatting van die gemiddelde bedryfsbesetting vir die lopende konjunktuursiklus. Die metode van die bewegende gemiddeldes oor die geskatte duur van een siklus, sê sewe tot nege jaar, gee hier met behulp van ekstrapolasie die beste resultate. $E_{n}$ as ons mos sorg dat ons geen eensydige fout maak by hierdie skattings nie, sal die som van die winste deur oordekking in goeie jare by benadering gelyk wees aan die verliese deur onderdekking in slegte jare.

En die oor- en onderdekkings is weer deur die parsiële kreditering bekend.

Vir die landbou moet ons in plaas van met die bedryfsbesetting rekening hou met die wisselvalligheid van die oeste. Dit is duidelik dat ons hier vir die kosprys- en winsberekening moet uitgaan van die gemiddelde opbrengs oor ' $n$ reeks van opeenvolgende jare; ons moet dus in jare van groot oeste'n reserwe opbou vir jare van klein oeste - ongeag die hoogte van die pryse - die ou politiek van Josef in Egipte, soos die Ou Testament ons dit beskryf.

Om te sien hoe ons die verliese deur prysdaling van grondstowwe kan opvang gaan ons weer uit van die stygende tak van die prysbeweging. Ons het alreeds gesien dat ons by stygende pryse die verkooprekening moet belas vir die vervangingswaarde; daardeur kry ons ' $n$ kreditpos op die prysverskillerekening wat hierdie rekening nagenoeg in ewewig bring. Dit beteken dat ons aan die einde van die boekingstydvak die grondstowwe nog teen die lae standaardpryse in die boeke laat staan, terwyl die inkooppryse en die markpryse gestyg het. Ons sal die voorraad dus teen ' $n$ hoër prys as die ou standaardprys in die balansstaat opneem maar reserveer die verskil - in reserwe juis voldoende om 'n ooreenkomstige prysdaling op te vang.

Vir die vaste bates soos masjiene en geboue moet ons daaraan dink, dat ons die jaarlikse afskrywing by stygende pryse moet bereken op die vervangingswaarde. By stasionêre bedrywe - streng geneem geld al hierdie beskouings die noukeurigste vir stasionêre bedrywe, maar ieder bedryf wat ' $n$ sekere omvang, leeftyd en verskeidenheid bereik het is vir die grootste deel stasionêr - by stasionêre bedrywe sal ons iedere jaar die afskywingsbedrae opnuut investeer. Die totale boekwaarde van alle bates saamgeneem bly dan ook in jare van oplopende pryse dieselfde en as hierdie styging in daling omslaan kry ons geen enkel verlies, tensy die pryse benede die oorspronklike peil sou daal.

So sien ons dat die moderne kalkulasie die eenvoudigste en afdoende oplossing gee vir die eliminasie van skynwinste wat juis in die teenswoordige tydperk van inflasie, wat oor die hele wêreld heers, so baie gevaarlik kan wees as ons hulle nie betyds onderken nie. 